\title{
A Critical and Comparative Study on Patient Information Leaflet, Primary Label and Primary Carton of a Carbapenem Dry Powder Injectable
}

\author{
Vamshi Krishna Tippavajhala', Lalit Kumar', Muddukrishna Badamane Sathyanarayana², Girish \\ Thunga $^{3}$, Viji Pulikkel Chandran ${ }^{3}$, Sohil Khan ${ }^{4}$, Girish Pai Kulyadi ${ }^{1, *}$
}

${ }^{1}$ Department of Pharmaceutics, Manipal College of Pharmaceutical Sciences, Manipal Academy of Higher Education, Manipal, Karnataka- 576104, INDIA.

${ }^{2}$ Department of Quality Assurance, Manipal College of Pharmaceutical Sciences, Manipal Academy of Higher Education, Manipal, Karnataka- 576104, INDIA.

${ }^{3}$ Department of Pharmacy Practice, Manipal College of Pharmaceutical Sciences, Manipal Academy of Higher Education, Manipal, Karnataka- 576104, INDIA.

${ }^{4}$ School of Pharmacy and Pharmacology, Quality Use of Medicines Network, Menzies Health Institute, Griffith University, Gold Coast, AUSTRALIA.

\begin{abstract}
Introduction: The main aim of this project was to study the patient information leaflets $(\mathrm{PIL})$, primary labels $(\mathrm{PL})$ and primary cartons for their adequacy, harmonization of printed text matter meeting regulatory requirements. Methods: The study involved comparative evaluation of PIL, PL and primary cartons of generic and innovator brands. Three different marketed brands of Meropenem for Injection IP were considered for this research study which include the innovator product, coded as brand $A$ and two generic products coded as brands $B$ and $C$ respectively. Additionally, a survey was conducted among nurses to check their awareness on errors in PIL's. Results: The study revealed that innovator product's PIL, PL and primary carton was free of critical, major and minor observations. However, generic brands PIL, PL and primary cartons were found to have all the three types of observations. Owing to routine work load and busy hospital ward activities, nursing staff were unaware of the errors found in the PIL's and assumed that the information was reliable. Conclusion: It's necessary to assure uniform and standard text matter content across PIL, PL and primary cartons thus, avoiding misleading information to healthcare professionals and patients.
\end{abstract}

Key words: Patient information leaflet, Primary label, Primary carton, Text matter, Harmonization.

\section{INTRODUCTION}

Injectable PILs provide detailed information on indications and usage, dosage and administration, dosage forms and strengths, contraindications, warnings and precautions, adverse reactions, drug interaction, use in specific population, over dosage, description, clinical pharmacology, non-clinical toxicology, clinical studies, references, pack presentation and storage/handling, patient counselling information and manufacturers name and complete address ${ }^{1-2}$ The PIL should be easily readable without any unambiguous language for better understanding to the healthcare professional or user community. Flesch Reading Ease (FRE) is a standard tool used commonly to evaluate legibility of written text matter. Importance should also be given to overall layout and design. ${ }^{3-6}$ The font size in PIL is also too small which makes the user very difficult to identify the typographical or any other type of mistakes. On the other hand, PL is a label affixed on immediate primary pack namely, ampoule or vial. PL gives important information
Submission Date: 16-07-2018; Revision Date: 03-09-2018; Accepted Date: 30-10-2018

DOI: 10.5530/ijper.53.1.23 Correspondence: Dr. Girish Pai K, Assistant Professor Selection Grade, Department of Pharmaceutics, Manipal College of Pharmaceutical Sciences, Manipal Academy of Higher Education,

Manipal, Karnataka- 576104, INDIA.

Phone: +919008135597

E-mail: girish.pai@manipal. edu

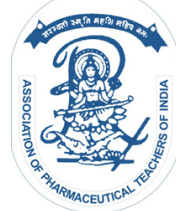

www.ijper.org 
about the strength of product, label claim and overages (if any), manufacturers address, precautions, storage, batch coding details like batch number, manufacturing and expiry dates. ${ }^{8}$ Labels that are difficult to read or ambiguous can also contribute to errors. Food and Drug Administration (FDA) recommends that the text on the container and carton labels should be generally oriented in the same direction; placed in the same field of vision (i.e., readable without having to turn or rotate the container) and surrounded by adequate white space to improve readability and avoid crowding. ${ }^{9}$ In the past, pharmaceutical firms have taken voluntary initiatives in correcting the label that could lead to errors. ${ }^{10}$ To cite a classic example, Birstol-Myers Squibb (BMS) took initiative on its own to rectify the labelling errors. ${ }^{11}$ Primary carton is the immediate pack which holds the drug product container (labelled vial or ampule). These primary cartons shall be packed into secondary carton (outer carton) and in turn these secondary cartons shall be packed in to shippers or corrugated boxes which forms tertiary packing. ${ }^{12}$ It is a regulatory requirement to have similar text matter on PL and primary cartons.

In normal practice, healthcare professionals refer PIL or PL or cartons before using the product. In view of this, manufacturer should take proper care in preparing and delivering right quality of PIL and PL with the supplied medicinal pack. At the same time, it is the responsibility of regulatory authorities to review and approve only correct PIL, PL and primary carton that is complete and adequate in all aspects. This is the first step before issuing any drug manufacturing license to manufacturer. Finally, it is the responsibility of manufacturer (Quality Control) to check, review every consignment of PIL, PL and primary carton before approving the consignment to be used for the batch. In this case, Quality Control plays a major role in sampling, reviewing and approving the right quality PIL, PL and primary carton. In case of any discrepancy found by the Quality Control, the packing materials shall be rejected.

The drug candidate chosen for this study is Meropenem, a widely used antibiotic. Meropenem and Meropenem for Injection are officially listed in Pharmacopoeias like USP, IP, etc. ${ }^{13-16}$ Meropenem belongs to the group of carbapenem antibiotics. Meropenem is bactericidal and acts by inhibiting cell wall synthesis. It has wide spectrum of antibacterial activity and is effective against gram positive and gram negative aerobic and anaerobic bacteria. Meropenem, when compared to imipenem is relatively stable to the renal dehydropeptidase and hence, can be administered without renal dehydropeptidase inhibitor. ${ }^{17-19}$ In the current study, we have explored our knowledge to review thoroughly the text matter on PIL, PL and primary cartons of three brands and to report discrepancies and typographical errors if any on PIL, PL and primary carton of approved marketed brands namely the innovator brand of AstraZeneca [Merrem (Meropenem) Injection Package Insert] coded as brand $A$ and marketed generic products coded as brands B and C.

\section{MATERIALS AND METHODS \\ Materials}

Selected brands (A, B and C), magnified lens, canon digital camera, standard references and innovators and generic manufacturers PIL, PL and primary cartons. A specially designed questionnaire was created for the nursing staff to assess their views on the reliability of PIL's.

\section{Methods}

Three different marketed brands of Meropenem for Injection IP (Dry powder injectable) were randomly chosen for this study. These brands were coded as brands A, $\mathrm{B}$ and $\mathrm{C}$ to avoid revealing the generic manufacturers name. ${ }^{20}$ Brand A was from Innovator Company and was selected as standard or benchmark product for this comparative study. Brands B and C are manufactured by well-established generic manufacturer having presence in regulated markets (Europe and USA). The marketed products of Meropenem for Injection IP of above three brands were procured from the same pharmacy outlet. Magnified lens was used to check and review PIL, PL and primary carton as the font size of printed text matter was small and not easily read by naked eye. PIL, PL and primary carton were independently and carefully reviewed, studied and were compared for presence of differences and errors with respect to standard PIL, PL and primary carton of innovator. Reviewed PIL, PL and primary carton was re-checked by a second reviewer to cross verify the findings or discrepancies. Observations were made particularly with respect to presence of essential information, relevancy of information printed and for typographical errors. Observations were captured for documented evidence by a digital camera and were noted down separately with respect to PIL, PL and primary cartons.

\section{Survey}

Since it is the responsibility of the nurses to properly read, understand, identify errors (if any) and communicate the same to healthcare professional or patient; a survey was conducted among the nursing staff of medicine wards of Kasturba Medical College (KMC) Manipal to assess their views on the reliability of information on PIL, PL and primary cartons. ${ }^{21}$ The questionnaire was 
circulated to nursing staff of the medicine wards after explaining the nature of study to them. Those who were willing to participate in the study were included. The responses to the questionnaire were collected and compiled. The data from the filled questionnaire were collected, data was compiled and analysed.

\section{RESULTS}

The critical review and thorough study of PIL, PL and primary cartons revealed few critical, major and minor typographical errors as detailed below.

\section{Storage Conditions Mentioned on the Primary Label and Carton}

The storage requirement varied from brand to brand as outlined below.

Brand A: Store below $30^{\circ} \mathrm{C}$ and protect from moisture.

Brand B: Keep in a cool dry place. Protect from light.

Brand C: Store below $30^{\circ} \mathrm{C}$ and protect it from light and moisture.

In addition, brand $\mathrm{C}$ showed differences between storage conditions mentioned in PIL, PL and primary carton (Figure 1). The storage conditions mentioned on PL and primary carton were matching whereas storage condition mentioned on PIL was different. PIL mentioned storage condition as "Keep in a cool dry place. Protect from light" whereas PL and primary carton mentioned "Store below $30^{\circ} \mathrm{C}$, Protected from light and moisture".

\section{Observations on PIL}

Critical observations in the PIL of brand C: Pharmacopoeial specification IP (Indian Pharmacopoeia) was missing for sodium carbonate as shown in Figure 2.

\section{Major Observations as Follows:}

As indicated in Figure 3, instructions for reconstitution of $0.25 \mathrm{~g}$ Meropenem for Injection IP were not included in case of brand $\mathrm{C}$ (as evidenced in Figure 3a) although the PIL presentation included Meropenem for Injection IP $0.25 \mathrm{~g}$ as shown in Figures $3 \mathrm{~b}$.

In case of brand $\mathrm{C}$, the table describing the recommended dosage schedule for adults with impaired renal function was wrongly described under the heading, "Adults with Hepatic insufficiency". However, there was a separate description under the same title explaining the dosage adjustment in hepatic insufficiency beneath the table indicating the dosage schedule for adults with impaired renal function again stating as "Adults with Hepatic insufficiency" as evidenced in Figure 4.

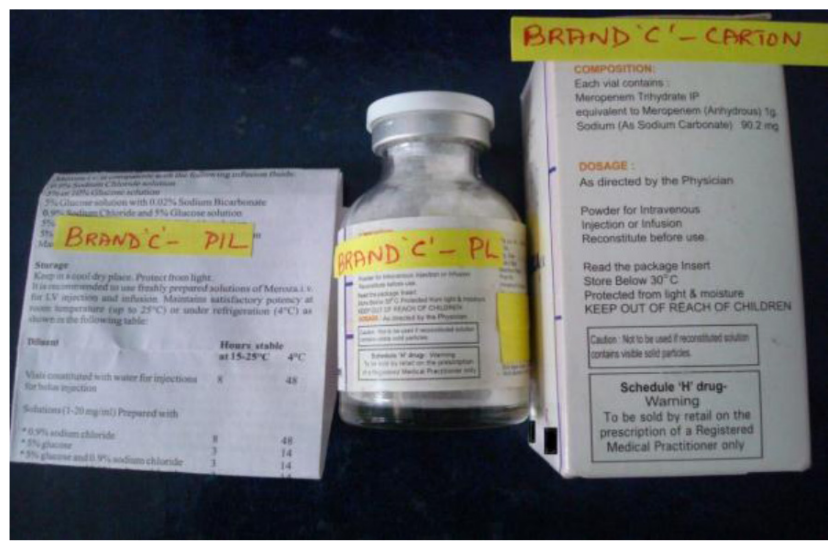

Figure 1: Evidence for discrepancies on storage conditions mentioned in PIL, PL and primary carton of Brand C.

\section{COMPOSITION} $10.25 \mathrm{~g}$

Each vial contains:

Meropenem Trihydrate IP equivalent to

anhydrous Meropenem $0.25 \mathrm{~g}$

Sodium Carbonate (Sodium $22.55 \mathrm{mg}$ )

$0.5 \mathrm{~g}$

Each vial contains:

Meropenem Trihydrate IP equivalent to

anhydrous Meropenem $0.5 \mathrm{~g}$

Sodium Carbonate (Sodium $45.1 \mathrm{mg}$ )

\section{$1 \mathrm{~g}$}

Each vial contains:

Meropenem Trihydrate IP equivalent to

anhydrous Meropenem $1 \mathrm{~g}$

Sodium Carbonate (Sodium $90.2 \mathrm{mg}$ )

Figure 2: Pharmacopoeial specification "IP" is missing for Brand C.

a

\begin{tabular}{|l|c|c|c|}
\hline Vial Size & $\begin{array}{c}\text { Amount } \\
\text { of Diluent } \\
\text { added (mL) }\end{array}$ & $\begin{array}{c}\text { Approximate } \\
\text { withdrawable } \\
\text { volume (mL) }\end{array}$ & $\begin{array}{c}\text { Approximate } \\
\text { Avernge Conc. } \\
\text { (mg/mL) }\end{array}$ \\
\hline $500 \mathrm{mg}$ & 10 & 10 & 50 \\
\hline $1 \mathrm{~g}$ & 20 & 20 & 50 \\
\hline
\end{tabular}

For infusion

Infusion vials ( $500 \mathrm{mg}$ and $1 \mathrm{~g}$ ) may be directly constituted with a compatible infusion fluid or an injection vial may be constituted. then the resulting solution added to an IV container and further diluted with an appropriate infusion fluid.

b

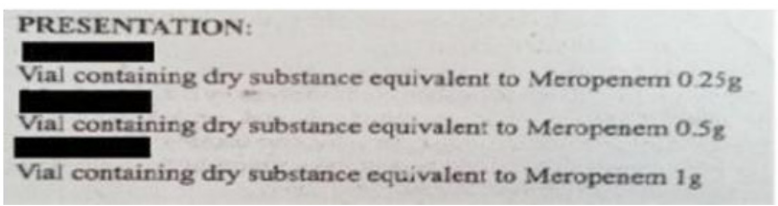

Figure 3: a) Evidence for missing of instruction for reconstitution of $0.25 \mathrm{~g}$ strength for brand $\mathrm{C}$. b) This evidence is

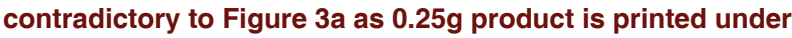
PIL presentation details of brand C. 


\begin{tabular}{|c|c|c|}
\hline $\begin{array}{c}\text { Table 1: Demographic Characteristics of Participants. } \\
\text { Demographic } \\
\text { factors }\end{array}$ & $\begin{array}{c}\text { Number of } \\
\text { participants }\end{array}$ & Percentage (\%) \\
\hline \multicolumn{3}{|c|}{ Sex } \\
\hline Male & 2 & $8 \%$ \\
\hline Female & 23 & $92 \%$ \\
\hline \multicolumn{3}{|c|}{ Age wise distribution } \\
\hline $20-25$ & 7 & $28 \%$ \\
\hline $26-30$ & 14 & $56 \%$ \\
\hline$>31$ & 4 & $16 \%$ \\
\hline \multicolumn{3}{|c|}{ Experience wise distribution (years) } \\
\hline $0-5$ & 19 & $76 \%$ \\
\hline $5-10$ & 4 & $16 \%$ \\
\hline $10-15$ & 1 & $4 \%$ \\
\hline $15-20$ & 1 & $4 \%$ \\
\hline
\end{tabular}

\section{Minor Typographical and Printing Errors in Brand C as follows:}

These typographical errors are underlined in red ink pen for ease of identification. There were 9 such errors shown sequentially in numbered pictures as detailed below under respective picture.

Overall quality of brand A (innovator) PIL, PL and primary carton was superior when compared to brands $\mathrm{B}$ and $\mathrm{C}$ with respect to quality of primary label pasted on vial, quality of packing materials used for primary carton and PIL. Other important features like, readability, print quality on PIL and PL and their finishing was at its best in innovator's brand.

\section{Survey}

The survey was conducted in Kasturba Medical College Hospital of Manipal University. A total of 25 nursing staffs participated in the survey.

As shown in Table 1, among the total population of nurses, $23(92 \%)$ were females and $2(8 \%)$ were males. Majority of respondents were in age group of 26-30 $(56 \%)$ followed by $20-25(28 \%)$ and $>31(16 \%)$. About $76 \%(\mathrm{n}=19)$ having $0-5$ years of experience, $16 \%(\mathrm{n}=4)$ having 5-10 years of experience and $4 \%(n=1)$ having 10-15 and 15-20 years of experience respectively.

\section{Nursing staff's views on PIL's}

Many of the respondents knew about the importance of patient information leaflets. Most of the participants found the information in the text with respect to reconstitution, microbial nomenclature, dosage adjustment and storage reliable for use.

In the present survey, all nurses agreed that PILs provides clarity. About $64 \%$ agreed that reading the PIL is time

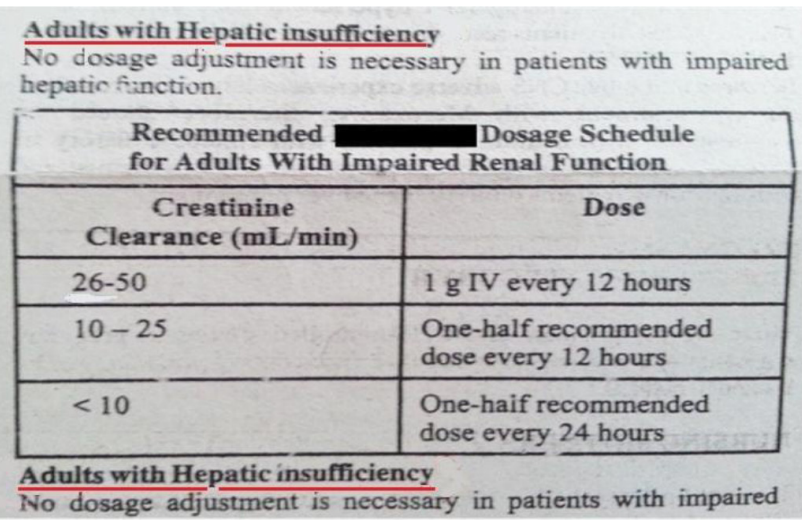

Figure 4: Brand C for evidence on discrepancy with respect to dose adjustment in case of impaired renal function and hepatic insufficiency.

consuming in view of hectic work load. $92 \%$ nurses agree that the PIL provides correct information on storage, but were unable to compare and report discrepancy in storage conditions mentioned on PIL, PL and primary cartons. With respect to reliability of text content, $72 \%$ agree that content is reliable. $60 \%$ of nurses could not identify errors in the provided PIL and only $24 \%$ found errors in PIL, since they reviewed PIL critically. $68 \%$ agreed that the information regarding reconstitution on PIL is correct. $80 \%$ agree that PIL provides information on dosage adjustment. 52\% nurses agreed that PIL can cause confusion in healthcare professionals.

\section{DISCUSSION}

PIL is like an encyclopaedia for user community. PL and primary carton on other hand should be in line with technical text matter printed on PIL and should not give scope for errors when compared. But unfortunately, we have observed major discrepancies between text matter printed on PIL, PL and primary carton, instead of being uniform across different printed packaging materials. These observations are discussed below.

- The recommended storage condition varied from brand to brand. The discrepancy included varied storage conditions, namely for storage temperature and protection from light when compared to brand A. Brand A did not mention about protection from light. Additionally, for brand $\mathrm{C}$, storage conditions mentioned on PL and primary carton were different from that of PIL as depicted in Figure 1, which was not uniform across the packaging text contents.

- As shown in Figure 2, the pharmacopoeial specification was missing for sodium carbonate in brand C. 
- As detailed in Figure 3, the instructions for dilution did not include the dilution volume for meropenem for injection $0.25 \mathrm{~g}$ in brand $\mathrm{C}$.

- As per the evidence shown in Figure 4, the heading for "dose adjustment in hepatic insufficiency" repeated twice instead of mentioning "dose adjustment in renal insufficiency" in brand C.

- Figure 5 evidenced us a total of 9 typographical errors in brand $\mathrm{C}$ which are of minor type. The names of microbes were not written according to binomial nomenclature system and spelling mistake was found for the word 'difficile'; instead wrongly typed as "dfificile"

- Figure 6 and 7 corresponding to brand $\mathrm{C}$ depicted that there were overprinting, smudging and spacing errors between the words "and pruritic" respectively.

- Figure 8 shows us evidence for spacing mistakes, spelling errors and a gross mistake of using the letters " $L V$ " instead of I.V.

As discussed above, in our study, we noticed many critical and major observations. These errors can be avoided at plant level provided if Quality Control does the review process properly without compromising on quality issues so that only right quality PIL, PL and primary cartons can be used for the batch. Minor observations like spelling errors or grammatical errors may not be serious as they do not have any negative impact on healthcare professionals (specifically nurses).

The present study revealed that most of the respondents $(60 \%)$ were not able to detect the errors in the PIL whereas, the remaining $(40 \%)$ agreed to the fact that PIL can cause confusion among the healthcare professionals. Nurse's perceptions about PILs was found to be good. However, they were unable to identify the errors in storage instructions. Due to busy working schedule of nurses, they could not find and report any errors. This is graphically shown in Figure 9.

\section{CONCLUSION}

This study concludes that there is an immediate need to supply the standard and corrected version of PIL in case of brand $\mathrm{C}$ and to harmonize the contents and pattern of PILs of innovator brand and generic brands (brand B and C) of Meropenem for Injection IP. Finally, it is the responsibility of manufacturer to use right quality of PIL, PL and primary cartons for the batch which in turn depends very much on competency level, technical expertise, subject knowledge and seriousness of Quality Control performing the sampling, review and approving these PIL and PL for a given product. In view of the lapses by Quality Control department, it is suggested

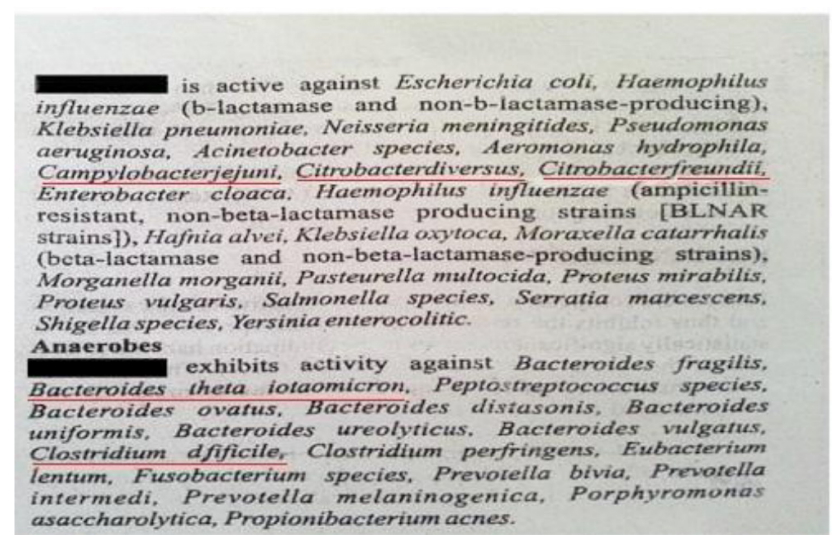

Figure 5: Typographical errors in brand C: errors in printing the names of the microbes according to standard binomial nomenclature system. Additionally, the last error shown in above picture depicts the spelling error for difficile being typed as "dfificile".

\section{CONTRAINDICATIONS}

is contraindicated in patients with known hypersensitivity to or to other drugs in the same class or in patients who have demonstrated anaphylactic reactions to betalactams.

\section{WARNINGS}

Serious and occasionally fatal hypersensitivity reactions have been reported in patients receiving treatment with beta-lactams. PRECAUTIONS

Seizures and other CNS adverse experiences have been reported during treatment with therefore should be administered with caution in patients with epilepsy, history of seizures or other neurological disorders. It should be administered with caution in patients with renalamdiltyer impairment.

Figure 6: Overprinting and smudging of printed matter can be seen as underlined in this snap. (Text matter is not clear for "renal and liver impairment").

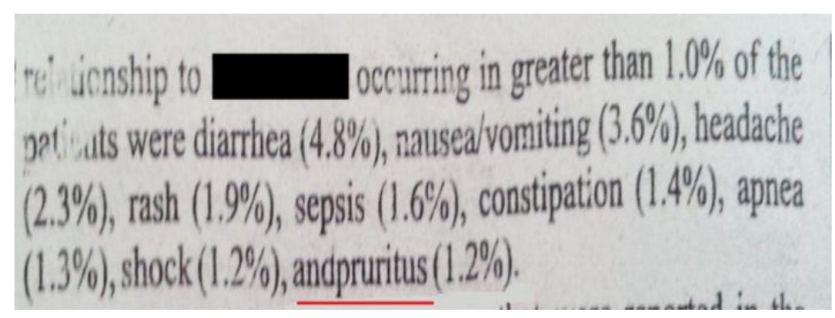

Figure 7: No space is provided in-between words of "andpruritus" which should be typed as "and pruritus" as seen in this snap.

that effective training and evaluation to be given to Quality Control staff including subjecting them for regular eye check-ups that shall avoid these types of defective PILs getting released into the market. 
a

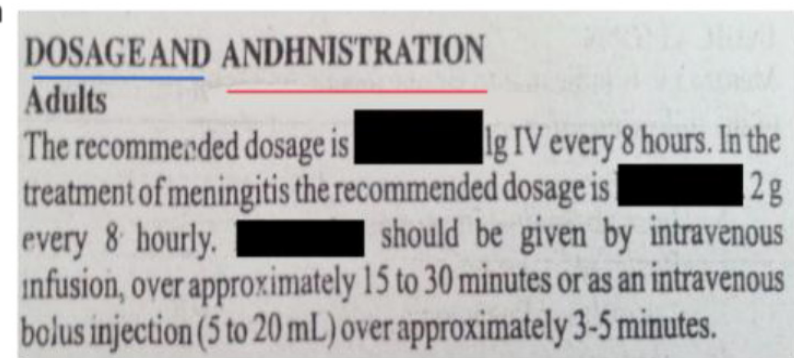

b

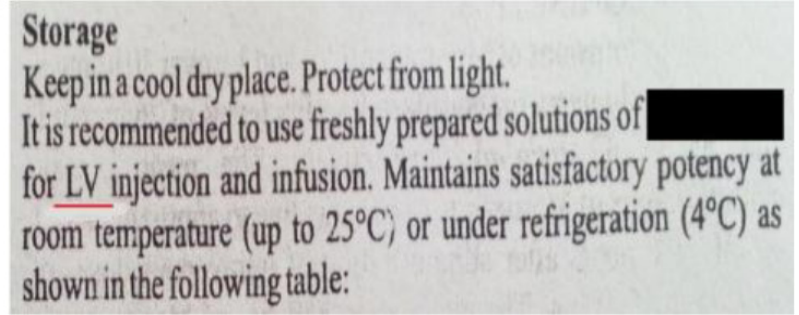

Figure 8: a) Under the heading Dosage and Administration, no space is provided in-between words "DOSAGEAND" which should be typed as "DOSAGE AND"; spelling of ADMINISTRATION was typed wrongly as “ANDHNISTRATION". b) Under the storage heading, "I.V injection" was wrongly typed as LV injection.

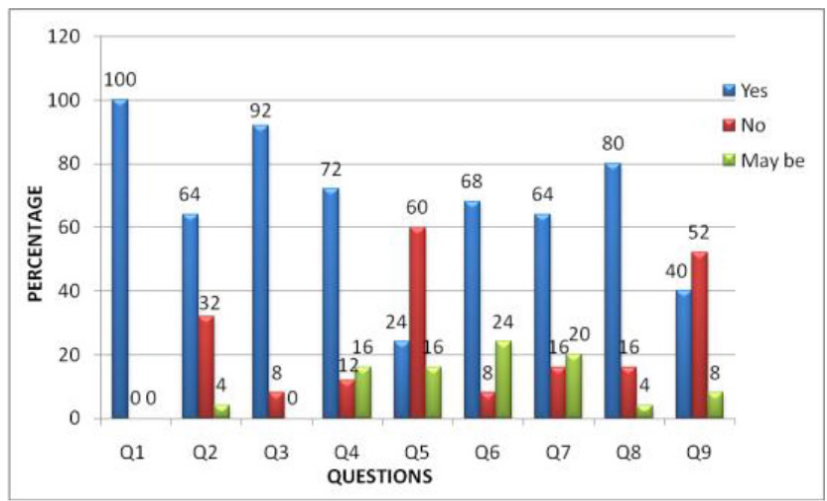

Figure 9: Nursing staffs views on PILs [Q1: Provides clarity, Q2: Time consuming, Q3: Provides information on storage, Q4: Reliability of text content, Q5: Presence of errors, Q6: Provides information on reconstitution, Q7: Provides information on microbial nomenclature, Q8: Provides information on dosage adjustment, Q9: Can cause confusion in Healthcare professionals].

\section{Practice Implications}

PIL and PL form important parts of market packs of dry powder injectables since they provide information on many of the important aspects such as reconstitution procedure of dry powder injectable, diluents to be used, precautions to be taken, dosage adjustments in renal and hepatic impairment etc. This information is frequently used by healthcare professionals. In this study, the errors encountered in PIL and PL of brand C can have a very high impact on therapy with Carbapenem antibiotic, i.e., Meropenem. The errors in printing the dosage adjustment of meropenem in the renal impairment can end up in administration of wrong dosage, which may further lead to serious complications, ultimately making the patient's life miserable and can be life threatening. The difference between storage conditions mentioned in PIL and that mentioned in PL can leave the patient and hospital pharmacist in confusion and also may lead to the storage of dry powder injectable under wrong temperature conditions and hence the deterioration of active pharmaceutical ingredient. The typographical errors in printing the names of microbes and failure to describe the Pharmacopoeial specification of sodium carbonate, although may not have very high impact on patient's therapy, render the PIL completely unfit to be inserted in the market pack from both regulatory and ethical point of view.

\section{ACKNOWLEDGEMENT}

Authors would like to thank Manipal College of Pharmaceutical Sciences and Kasturba Medical College of Manipal Academy of Higher Education for providing the facilities to conduct this study.

\section{CONFLICT OF INTEREST}

The authors declare that there is no conflict of interest.

\section{ABBREVIATIONS}

PIL: Patient Information Leaflet; PL: Primary Label; IP: Indian Pharmacopoeia; FRE: Flesch Reading Ease; FDA: Food and Drug Administration.

\section{REFERENCES}

1. Merrem $^{\circledast}$ I.V. (meropenem for injection). Available from: https://www. accessdata.fda.gov/drugsatfda_docs/label/2008/050706s022lbl.pdf. Accessed on 02/02/2018.

2. Gibbs S, Waters WE, George CF. The benefits of prescription information leaflets (1). British Journal of Clinical Pharmacology. 1989;27(6):723-739.

3. Adepu R, Swamy MK. Development and Evaluation of Patient Information Leaflets (PIL) usefulness. Indian J Pharm Sci. 2012;74(2):174-8. https://doi. org/10.4103/0250474X.103857.

4. Judy RM, Patrick AC, Heather RY. Rain, smog, fog and printed educational Material. J Pharm Pract Res. 2003;33(4):284-5.

5. Adepu R, Nagavi BG. Patient information leaflets design and Readability. Pharma Rev. 2003;2(7):135-43.

6. Spadaro DC, Robinson LA, Smith LT. Assessing readability of patient information materials. Am J Hosp Pharm. 1980;37(2):215-21. [PubMed: 7361793].

7. Bernardini C, Ambrogi V, Fardella G, Perioli L, Grandolini G.. How to improve the readability of the patient package leaflet: a survey on the use of colour, print size and layout. Pharmacol Res. 2001;43(5):437-44. https://doi. org/10.1006/phrs.2001.0798.

8. Zadbuke N, Shahi S, Gulecha B, Padalkar A, Thube M. Recent trends and future of pharmaceutical packaging technology. Journal of Pharmacy 
and Bioallied Sciences. 2013;5(2):98-110. https://doi.org/10.4103/09757406.111820

9. Guidance for Industry, Safety Considerations for Container Labels and Carton Labeling Design to Minimize Medication Errors. FDA, U.S. Department of Health and Human Services. 2013

10. Murphy J, Gamble G, Sharpe N. Readability of subject information leaflets for medical research. N Z Med J. 1994;107(991):509-10. [PubMed: 7830982]

11. Kenagy JW, Stein GC. Naming, labeling and packaging of pharmaceuticals. Am J Health Syst Pharm. 2001;58(21):2033-41. [PubMed: 11715825].

12. Pareek V, Khunteta A. Pharmaceutical Packaging: Current Trends and Future. Int J Pharm Pharm Sci, 2014;6(6):480-5.

13. Meropenem. Indian Pharmacopoeia. The Indian Pharmacopoeia Commission, Ministry of Health and Family Welfare, Government of India, Ghaziabad. 2007;2:737.

14. Meropenem Injection. Indian Pharmacopoeia. The Indian Pharmacopoeia Commission, Ministry of Health and Family Welfare, Government of India, Ghaziabad. 2007;2:738.
15. Meropenem. The United States Pharmacopoeia XXIX, The National Formulary 24, United States Pharmacopoeia Convention, USA: Rockville, MD. 2006;USP29-NF24:1349.

16. Meropenem for Injection. The United States Pharmacopoeia XXIX, The National Formulary 24, United States Pharmacopoeia Convention, USA: Rockville, MD. 2006;USP29-NF24:1351.

17. Wisher D. Martindale: The Complete Drug Reference. $37^{\text {th }}$ edition. Volume A. 2011;323-4.

18. Baldwin CM, Lyseng WKA, Keam SJ. Meropenem: a review of its use in the treatment of serious bacterial infections. Drugs. 2008;68(6):803-38.

19. Edwards JR. Meropenem: a microbiological overview. J Antimicrob Chemother. 1995;36(Suppl A):1-17.

20. Chermak TE, Lambert BL. Descriptive analysis of primary package labels from commercially available prescription solid oral dosage form drugs. J Am Pharm Assoc. 2009;49(3):399-406. https://doi.org/10.1331/ JAPhA.2009.07137.

21. Mumford ME. A descriptive study of the readability of patient information leaflets designed by nurses. J Adv Nurs. 1997;26(5):985-91. [PubMed: 9372404].

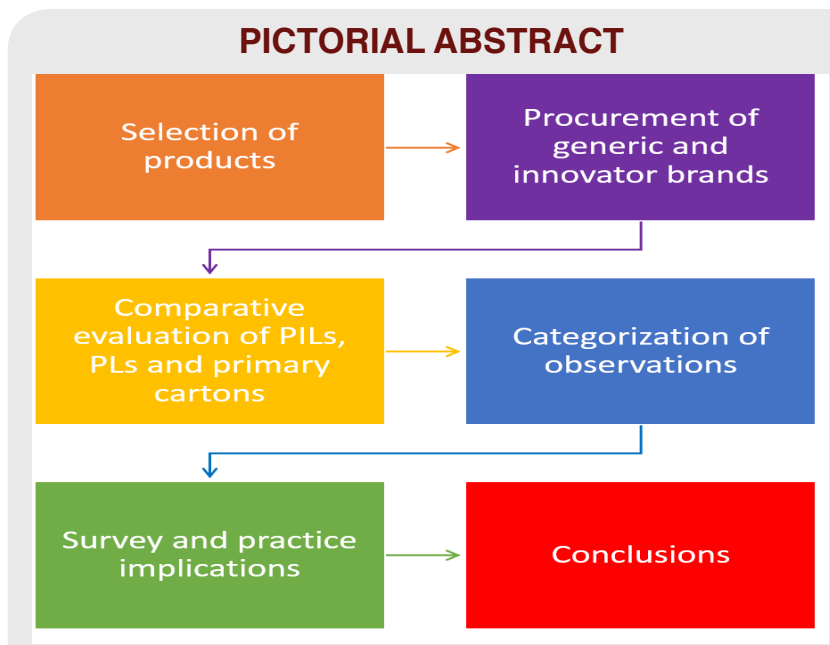

\section{SUMMARY}

- This research study revealed various critical, major and minor observations on generic brands PIL, PL and primary cartons which were overlooked by the nursing staff owing to their routine work load and busy hospital ward activities and assumed that the information was reliable.

- So it is required to ensure the text matter content across PIL, PL and primary cartons is uniform and correct thus avoiding any misleading information to healthcare professionals and patients.

\section{About Authors}

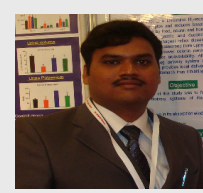

Dr. Vamshi Krishna Tippavajhala received his bachelor's and master's degrees in pharmacy from Kakatiya University, India. He worked on "Multiparticulate drug delivery systems for Tuberculosis therapy" during his PhD in Manipal University, India and on "Confocal Raman spectroscopic analysis of cosmetic permeation through human skin" for his postdoctoral fellowship in the Laboratory of Biomedical Vibrational Spectroscopy, Universidade do Vale do Paraiba, Brazil. He has 10 years of professional experience. His area of research expertise includes formulation development of novel drug delivery systems. He has published more than 40 research and review articles in peer reviewed journals. Presently he is working as Associate Professor in Manipal College of Pharmaceutical Sciences, Manipal Academy of Higher Education, Manipal, India.

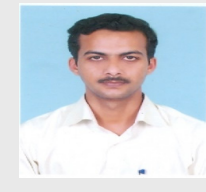

Dr. Lalit Kumar is presently working as an Assistant Professor (Senior Scale) at Department of Pharmaceutics, Manipal College of Pharmaceutical Sciences, Manipal Academy of Higher Education, Manipal, Karnataka, India. Dr. Lalit is engaged in teaching and research since nine years. His core area of research is novel formulation developments. He has drawn several research grants from numerous funding agencies such as Karnataka State Vision Group of Science and Technology (VGST), Bangalore; All India Council of Technical Education (AICTE), New Delhi; Science and Engineering Research Board (SERB), New Delhi; Indian Council of Medical Research (ICMR), New Delhi, etc. He is a life member of Association of Pharmaceutical Teachers of India (APTI), Association of Community Pharmacist of India (ACP), Society of Pharmaceutical Education and Research (SPER), etc. He has published more than 45 research and review articles in peer reviewed journals. 


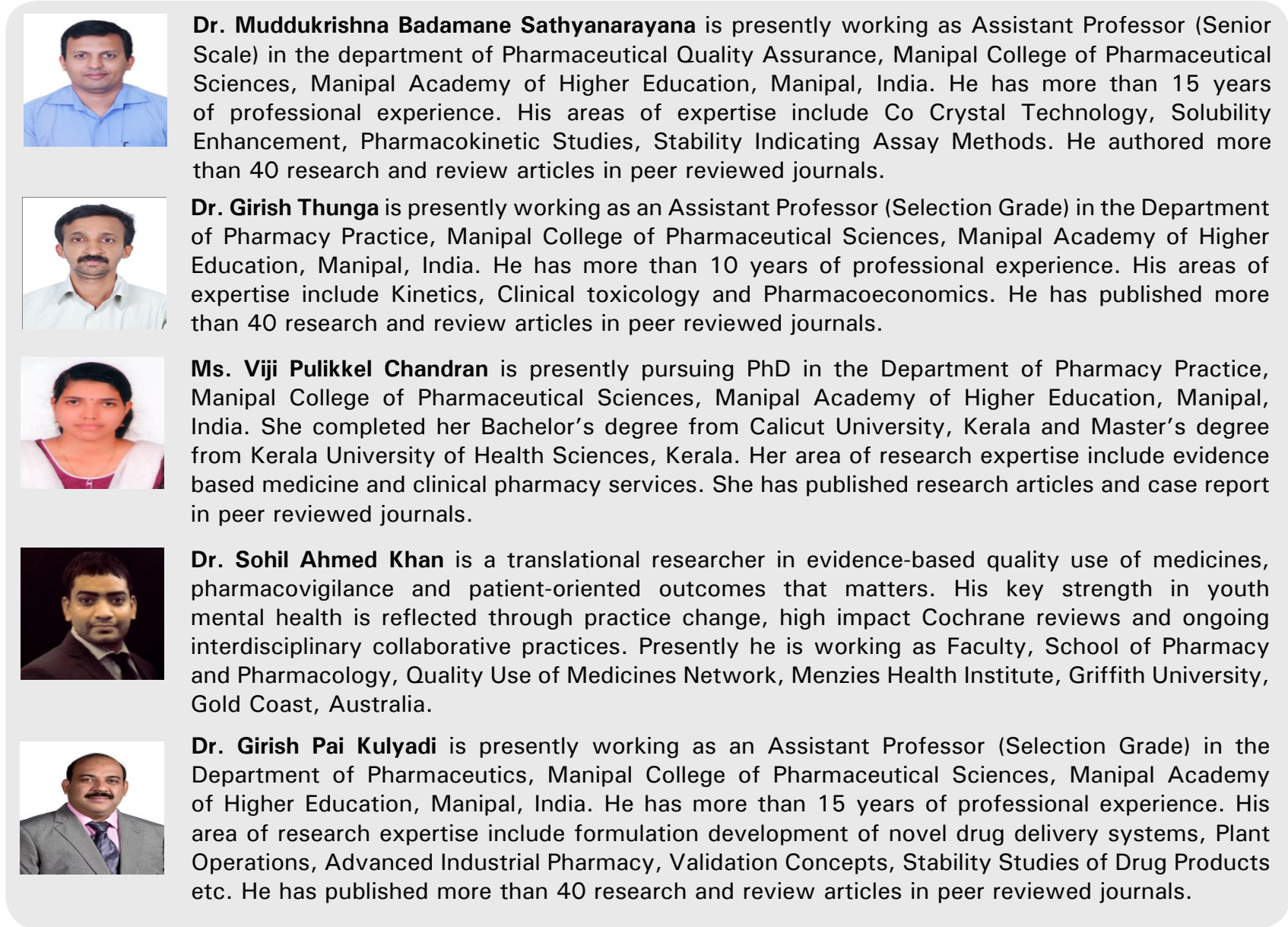

Cite this article: Tippavajhala VK, Kumar L, Muddukrishna BS, Thunga G, Viji PC, Sohil K, Pai GK. A Critical and Comparative Study on Patient Information Leaflet, Primary Label and Primary Carton of a Carbapenem Dry Powder Injectable. Indian J of Pharmaceutical Education and Research. 2019;53(1):178-85. 